TPeriodica Polytechnica

61(3), pp. 640-651, 2107

https://doi.org/10.3311/PPci.10418

Creative Commons Attribution (i)

RESEARCH ARTICLE

\section{Analysis of Gothic Architectural Details by Spatial Object Reconstruction Techniques}

\author{
Árpád Somogyi ${ }^{1 *}$, Krisztina Fehér ${ }^{2}$, Tamás Lovas ${ }^{1}$, Balázs Halmos ${ }^{2}$, \\ Árpád Barsi ${ }^{1}$
}

Received 16 December 2016; Revised 13 January 2017; Accepted 15 January 2017

\begin{abstract}
The paper focuses on the $3 D$ data acquisition technologies that support capturing the geometry of medieval architectural fragmented stones. High-resolution models of such fragments enable the analysis of profile shapes as well as the marking lines and curves left by the instruments of stonemasons, and therefore, indirectly, identifying connections between several master builders could become possible. Considering the requirements of historical analysis and the fact that the investigated stones are under monument protection, the authors decided to use remote sensing technologies, such as structured light scanning, terrestrial laser scanning, depth camera and image-based reconstruction.

The paper evaluates the discussed technologies based on the accuracy and geometric resolution of the obtained $3 D$ models. Besides technical parameters, time and cost requirements also have been investigated. The paper gives an overview on the advantages and shortcomings of the applied data acquisition technologies and of the provided end-products.
\end{abstract}

\section{Keywords}

gothic architectural detail, object reconstruction, SLS, TLS, kinect

\footnotetext{
${ }^{1}$ Department of Photogrammetry and Geoinformatics, Faculty of Civil Engineering, Budapest University of Technology and Economics, Müegyetem rkp. 3., H-1111 Budapest, Hungary, e-mail: somogyi.arpad@epito.bme.hu ${ }^{2}$ Department for History of Architecture and of Monument, Faculty of Architecture, Budapest University of Technology and Economics, Müegyetem rkp. 3., H-1111 Budapest, Hungary, e-mail: feher.krisztina@eptort.bme.hu

${ }^{*}$ Corresponding author, email: somogyi.arpad@epito.bme.hu
}

\section{Introduction}

The survey of different objects, constructions and sites always plays an essential role in any kind of engineering process, architectural project, monument reconstruction or even theoretic research. Like in various professions, survey documentation is essential in architecture, however, its form and method depends on the specific requirements of each project. Until recently surveying was part of the architects' discipline, but since advanced technologies have been introduced in architectural surveying, the involvement of measuring specialists becomes inevitable.

The secret of geometric proportioning methods of Gothic master builders has been in the focus of research for more than one and a half centuries [12]. The latest improvements of measuring technologies and computer aided analysis enable to put this subject in a new context. The main goal of the present paper was to investigate the potential of cutting edge $3 \mathrm{D}$ data acquisition and modelling technologies to support surveying medieval architectural profiled carved stones.

Examining architectural details instead of whole buildings is a prominently important aspect of the research. In case of whole building compositions, the building eventually constructed can considerably differ from the plan due to changes of conception, later transformations or deformations. The profiled stone elements however are much more likely to be closer to their ideal shape so the research of details allows analyzing the geometric strategies of the original conceptions. The examination of profile shapes as well as the marking lines and curves left by the instruments of stonecutters is of high importance. The surveying method to be accomplished is appropriate for scanning and modelling several pieces of stones with a result as precise as possible. This level of accuracy is however limited by the applied devices and the abrasion and original carving inaccuracies also must be taken into consideration. Besides manual measurements four digital surveying technologies were applied and compared: a terrestrial laser-scanner (TLS), a structured light scanner (SLS), a close-range photogrammetry and a depth camera.

The experiment was based on the survey of four profiled stones selected from the medieval stone collection of the 
Budapest History Museum which were excavated from the former Royal Castle of Buda (Budapest, Hungary). This stone collection consists of the remaining construction elements of the former gothic periods of the royal residence as well as the surrounding buildings in the Buda Castle Hill from the era of Louis I (1342-1382), Sigismund of Luxemburg (1387-1437) and Vladislaus II (1490-1516). The medieval parts of the palace disappeared during the Great Turkish War in the 17th century and the majority of the gothic stones had been reused as building material. The remains of the medieval residence of Hungarian kings have only been partly excavated, which makes the complete theoretic reconstruction of the buildings impossible [13], even though the analysis of the collection of thousands of architectural fragments has provided valuable data on the medieval periods of the royal palace. The objective of our research in the long run is to refine the chronology of medieval Buda Castle. The conclusions derived from the analysis of the geometry and proportioning methods of architectural details can be added to former morphologic observations. Comparing the geometrical principles of architectural details correlations between different Hungarian or European medieval buildings can be discovered.

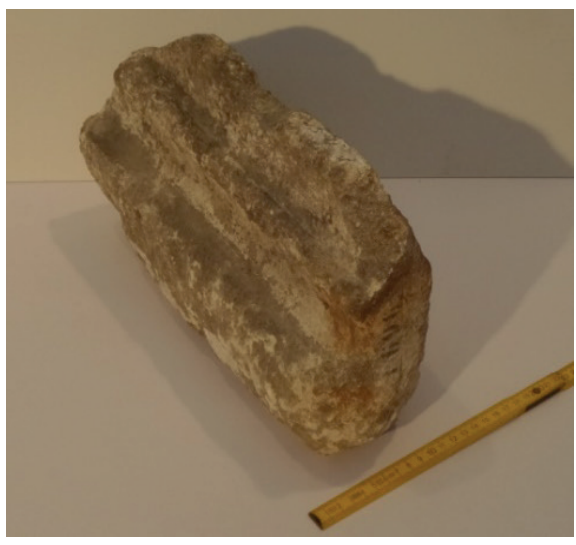

a) Profiled rib element \#0048

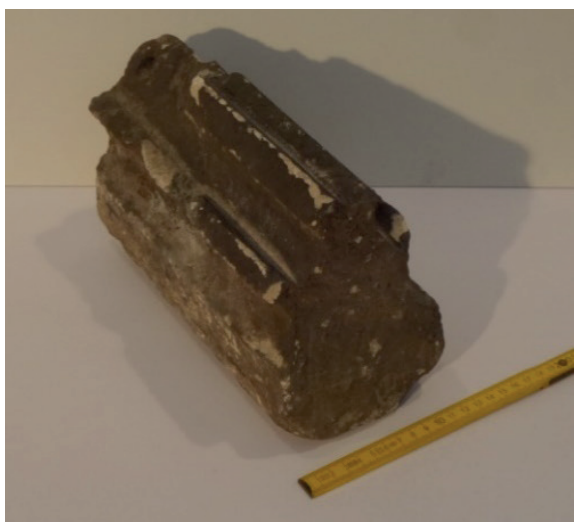

c) Profiled rib element \#0068

\subsection{Objects of analysis}

A former catalogue and topographic systematization of the medieval stone collection related to the royal palace was created by Nagy in 1994 [14], but to fulfil the requirements of the present research a new catalogue was initiated. Four carved stones have been selected from the collection to be measured with reference numbers of \#0048, \#0051, \#0068 and \#0121 in our latter catalogue. Selecting the four items for our case study, several aspects were considered, such as the diversity of their one-time structural role, material, dimensions, shape and condition. Three of them are ribs from former vaultings (\#0048, $\# 0051, \# 0068$ ) but the fourth is a mullion (\#0121) carved of a harder travertine while the others are of porous limestone. In a study of Várnai the profile of two of the ribs (\#0048, \#0068) are considered to be typical in Buda in the first half of the 16th century [15], while the dating of the other two stones is uncertain.

The stone $\# 0048$ is a general rib element probably from a cross rib vault. The profile - named "threefingered" by Nagy consists of a main upper molding and two smaller on both sides followed by gouges. Regarding its condition this is the most fragmentary of the four items, however its profile shape can be reconstructed. This stone serves an interesting example as the curve of the former rib construction is visible in its length. Its bath limestone material is quite easily weathering. (Fig. 1a)

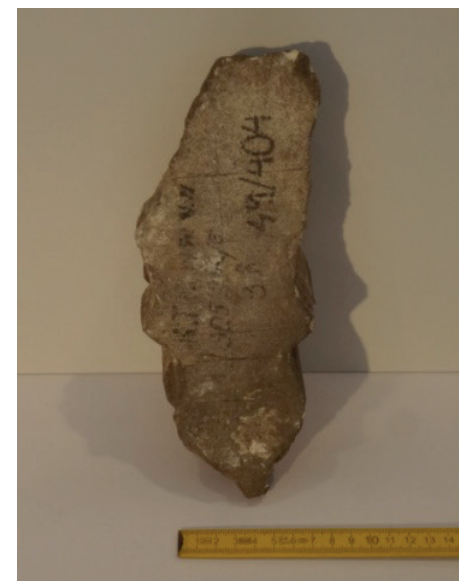

b) Profiled rib element \#0051

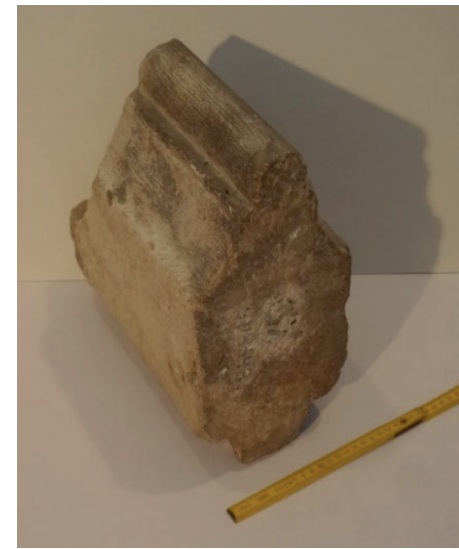

d) Profiled rib element \#0121

Fig. 1 The gothic architectural details 
The identification of the item \# 0051 raises several questions. It is quite presumable that it served as a rib element of probably a lierne vault (accounted by its quite small scale), however its carving might have never been finished. The upper part of the profile is in a good condition due to its porous limestone material. The fitting surface of the fragment is oblique and scratched with lines tracing the main points of the profile shape. (Fig. 1b)

The stone \#0068 is also a rib element. The shape of its profile - called 'horned' by Nagy after its double upper molding - is sharp despite of its several fractured parts. As its material is porous limestone, the traces held by stone carvers' tools can be seen on its surfaces. (Fig. 1c)

The item \#0121 is a mullion element that differs from the other three in several aspects. According to its constructional role, its material (travertin) is much harder than the rocks typically used for the vaulting elements. Because of the solidity of the hard limestone material the moldings require more precise carving and are mostly unscathed. (Fig. 1d)

\subsection{Traditional measurement method}

In case of historical monuments, the survey fundamentally supports the analysis of the building. Having always been connected to monument preservation, manual survey has a considerable tradition in architectural projects. For improving measuring accuracy several special devices are available, and creativity plays also an important role in the process. The shape, size and other properties of the item determine the selection of the survey methods. In architectural research whole buildings, structural parts and details all can be in the focus of exploration. In our case the surveying accuracy is essential, however the fractured state of the stones usually limits the success of manual survey. Laser-based measuring technologies provide more precise survey data, which improves the chances of finding the correct geometry of the particular profile. These instruments allow surveying even whole buildings in a precise manner, which however - as Murray have expressed - does not answer the main questions of the subject automatically, but provides a valuable tool for analysis [16]. Therefore the laser-based surveys undoubtedly provide a precise mapping, the comprehension process however still needs the direct connection between researcher and object.

The most substantial bibliographic work on the practical aspects of manual survey was published by Hajnóczi in 1956, expounding the proper use of necessary equipment, the creation of initial hand drawings ('manual') and measure technologies [17]. Further bibliography of manual survey from the theoretic point of view is also rich $[18,19]$.

Defining the reference frame is essentially important in the survey. In case of small items, like profiled stones for instance, the use of relative systems is sufficient, while geodetic referencing might be needed for large scale objects or structures. The latter method, called true-to-form survey, is suitable for detecting geometric anomalies and distortions of buildings and furthermore - in accordance with the principles led by the discipline of 'Bauforschung' - it is the most essential part of the research of architectural items [20].

The manual survey of the four profiled stones represents the main characteristics of this method. By drawing freehand sketches an ideal profile shape can be produced, which is useful as the negligible anomalies and visible imperfections can be filtered out in one step. (Fig. 2) On the other hand, this involves the possibility of significant mistakes if our preconception about the form is incorrect. Measuring the dimensions, the main geometric patterns as proportions, symmetry or asymmetry of the profile can be noticed. The drawn cross section however, is measured on different points of the stone because of the several fractured parts, consequently the result neglects the possible distortions.
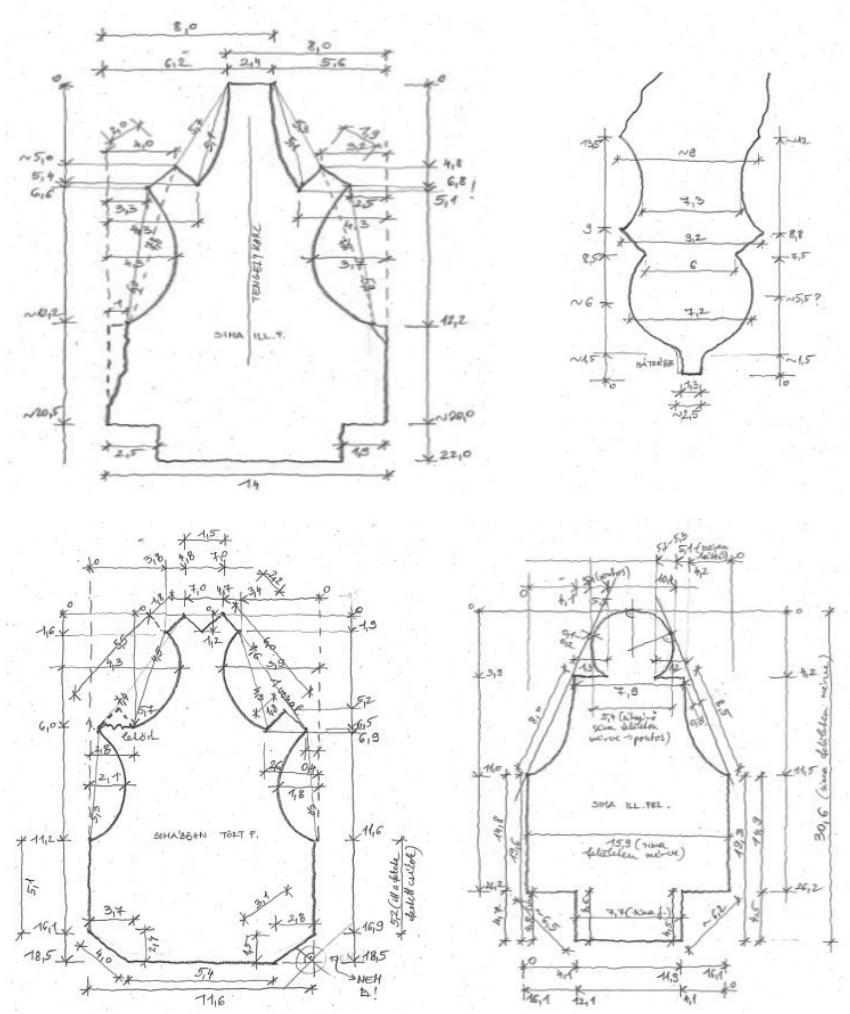

Fig. 2 Manual drawings of the four profiled stones (\#0048, \#0051, \#0068, \#0121)

The research of Möller in the 1910's is entirely relevant to mention as his intention was to learn the geometric systems of profiled architectural elements by surveying them as precisely as possible - exactly the same focus as of the present research project [21]. Besides Möller, several contemporary researchers can be also mentioned who studied Gothic architectural details applying laser based surveying methods. The work of Szekér focuses on whole building structures based on accurate laser scanning technology and using medieval sources on Gothic geometrical constructing methods to reconstruct the missing elements [22]. Szőke applies laser scanning as the basis of his methodology elaborating theoretic reconstructions of various 
Hungarian lierne vaults. Having surveyed the remaining rib elements, he builds up the whole vaultings by computer aided modelling programs [23]. The research of Bauer and Lauterbach is dealing with analyzing medieval geometry and constructional principles [24, 25]. In addition, the authors also cooperated with the Budapest History Museum for surveying late Gothic rib elements of the medieval stone collection.

\section{The applied reconstruction techniques}

Wide spectrum of the currently available reconstruction techniques was aimed to use to reconstruct stone fragments, remains. The applied measurement methods and costs are quite different: structured light scanning, pixel based reconstruction, terrestrial laser scanning, and depth camera were used.

The principle of the structured light scanning (SLS) dates back to the 80 's [4]. This technique is also called active stereo vision. The main difference compared to the two camera based close range photogrammetry systems is that a camera has been replaced by an active light source (Fig. 3a). A pre-defined pattern is projected onto the object, then the entire scene is captured by a specific sensor. To reconstruct the object geometry, the system uses the original pattern and the obtained one distorted by the object's shape during the projection.

In the recent years automatic image orientation is a very active field of the photogrammetric community. The developed methods enable to create point clouds and surface models based on image sequences (Fig. 3b). The spatial reconstruction is carried out by several steps, which are feature extraction and matching [2, 3], then error filtering [1]. Typically the calculated sparse point cloud is not suitable for further modelling, therefore a densification phase is essential. This step is called pixel-wise surface reconstruction.

The first appearance of terrestrial laser scanners (TLS) goes back to the 90's, but now this ground-based, active method has been widespread in many areas of the engineering practice. Terrestrial laser scanners can be categorized by the principle of the distance measurement, which strongly correlates to both the available measurement range and the resulting accuracy. Two main ranging technologies are used in laser scanners: time of flight (ToF) and phase based (PB) method. The advantage of long ranges (several $\mathrm{km}$ ) of the ToF scanners implies reasonable accuracy (4-5 mm), whilst the PB scanners' range is restricted to some hundred meters but the ranging accuracy is better (2-3 $\mathrm{mm})$. From the horizontal and vertical scanning angle and the distance of a point its orthogonal coordinates $(\mathrm{X}, \mathrm{Y}, \mathrm{Z})$ can be calculated (Fig. 3c). As an active technology the survey can be carried out even at night or at dark places (e.g. passages and caves), and, obviously, the measurement is not sensitive to shadows [6]. In most cases prebuilt or mounted cameras are available, which permit the "colorization" of the point cloud [5].

Depth cameras produce images containing distance values in pixels (Fig. 3d). The device emits (typically infrared) light pulses like a flash and a matrix sensor records the distance of each pixel. Cartesian coordinates can be calculated if the depth information and the planar coordinates of the pixel are available. The result is a point cloud about the range of the sensor. Typically there are two different technologies for the range measurements: the time of flight (ToF) and the optical triangulation. The high sampling rate, typically 10 to $90 \mathrm{fps}$, requires rapid sensor read out, therefore depth cameras mostly apply CMOS (complementary metaloxide-semiconductor) sensors. High image resolution (more than 1-2 Megapixels) is generally not available. The point cloud can be colorized by an RGB camera by transforming its image into the same point of view as the depth sensor.

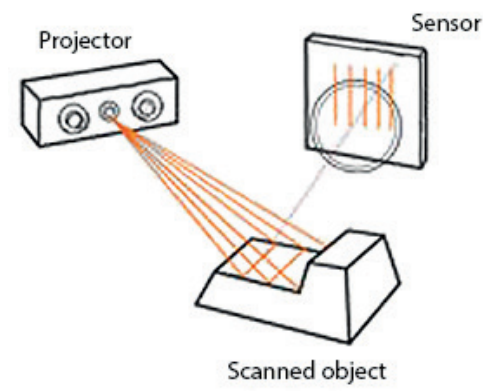

a) Measurement method of the structured light scanners (http://rapidform.com)

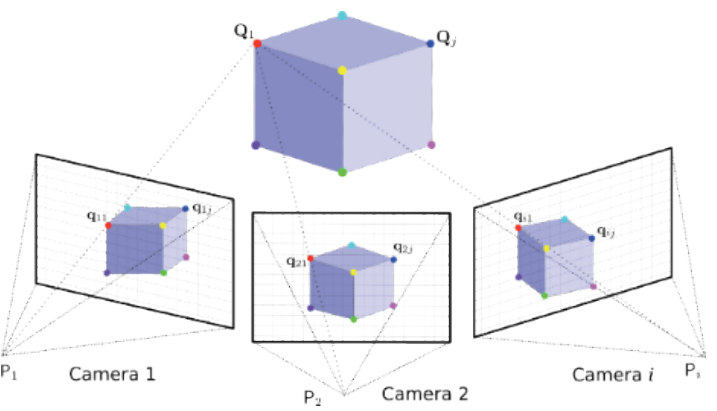

b) The discipline of automatic image orientation (http://michot.julien.free.fr/)

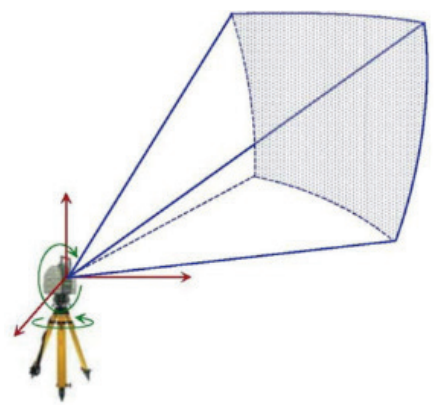

c) The terrestrial laser scanning coordinate measurement (http://mdpi.com)

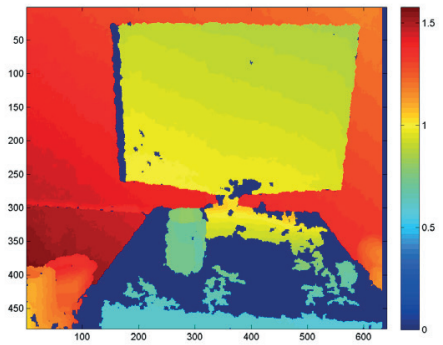

d) A directly measured depth image (https://grapeot.me)

Fig. 3 The applied reconstruction techniques 


\subsection{The instruments and the measurement}

\subsubsection{Artec Eva}

The SLS measurement was carried out by an Artec Eva (Tab. 1) scanner. It has two cameras, one 3D projector and thirteen flashes. One camera and twelve flashes are responsible for the texture and the rest for capturing the spatial geometry. The maximum measurement rate ( $16 \mathrm{fps}$ ) produces 2 million points per second [9]. This instrument has the highest accuracy among the investigated devices and technologies, therefore this measurement can be considered as reference.

Table 1 Technical parameters of Artec Eva

\begin{tabular}{cc}
\hline Measurement method & Optical triangulation \\
\hline Nominal 3D resolution & $0.5 \mathrm{~mm}$ \\
Nominal 3D point accuracy & $0.1 \mathrm{~mm}$ \\
Working distance & $0.4-1 \mathrm{~m}$ \\
Video frame rate & $16 \mathrm{fps}$ \\
Data acquisition speed & 2 million points / sec \\
Color information & Available \\
\hline
\end{tabular}

The architectural details have been surveyed at a distance of nearly $0.5-1$ meter far from the objects with $10-12$ fps recording frequency, while adequate overlap was ensured between each shot. Several scenes were captured in each position of the stones resulting independent point cloud patches. These were aligned by an iterative closest point (ICP) method. Four reference mesh models (0048, 0051, 0068 and 0121) were produced (Tab. 2).

Table 2 The produced mesh models with Artec Eva

\begin{tabular}{ccccc}
\hline & $\mathbf{0 0 4 8}$ & $\mathbf{0 0 5 1}$ & $\mathbf{0 0 6 8}$ & $\mathbf{0 1 2 1}$ \\
\hline $\begin{array}{c}\text { Number of } \\
\text { triangles }\end{array}$ & 1885740 & 528604 & 1705002 & 3231876 \\
\hline
\end{tabular}

\subsubsection{Canon EOS 760D}

The photos were taken with a Canon EOS 760D DSLR camera. The images were shot at maximum resolution $(6000 \times 4000$ pixel) under proper lighting circumstances. Feature point extraction and matching is a tough task in case of homogenous surfaces such as the investigated stones. For this reason, the stone fragments were put on a calibration test sheet (Fig. 4). The data caption was performed in three different positions so that always another side was hidden. The images were captured with reasonable distribution and proper overlap. The image processing (the pixel based object reconstruction) was carried out by Agisoft Photoscan [10] (Tab. 3).
Table 3 Features of the pixel based spatial reconstruction

\begin{tabular}{|c|c|c|c|c|}
\hline & 0048 & 0051 & 0068 & 0121 \\
\hline $\begin{array}{c}\text { Number of all/aligned } \\
\text { images (position I) }\end{array}$ & $30 / 29$ & $27 / 26$ & $27 / 27$ & $24 / 24$ \\
\hline $\begin{array}{l}\text { Number of all/aligned } \\
\text { images (position II) }\end{array}$ & $35 / 35$ & $27 / 25$ & $19 / 16$ & $25 / 25$ \\
\hline $\begin{array}{l}\text { Number of all/aligned } \\
\text { images (position III) }\end{array}$ & $34 / 34$ & $28 / 28$ & $27 / 24$ & $18 / 18$ \\
\hline $\begin{array}{l}\text { Number of points } \\
\text { (position I) }\end{array}$ & 3920629 & 47190509 & 49670406 & 3216417 \\
\hline $\begin{array}{l}\text { Number of points } \\
\text { (position II) }\end{array}$ & 4656570 & 38183023 & 32870764 & 3457033 \\
\hline $\begin{array}{l}\text { Number of points } \\
\text { (position III) }\end{array}$ & 4232205 & 40466374 & 42526307 & 3128080 \\
\hline $\begin{array}{l}\text { Number of points after } \\
\text { outlier and non-stone } \\
\text { point removal }\end{array}$ & 1032640 & 2429820 & 8673378 & 1088790 \\
\hline
\end{tabular}

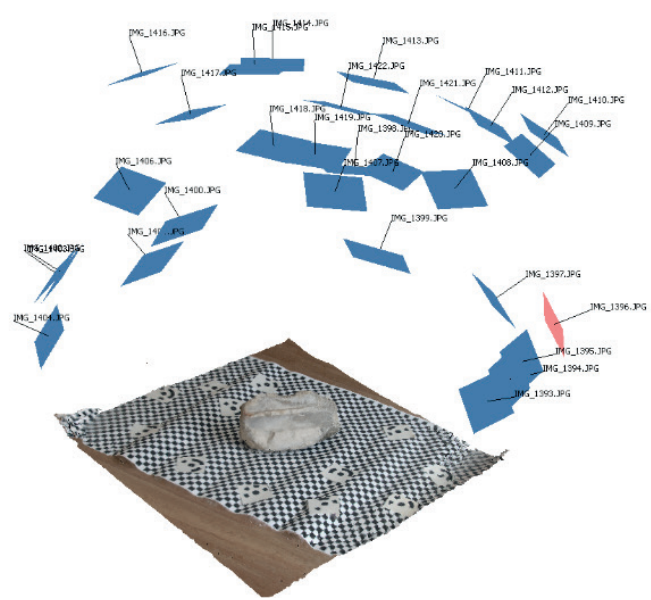

Fig. 4 Estimated image orientations and dense point cloud (ID 0048, position I)

\subsubsection{Faro Focus 3D 120}

The terrestrial laser scanning was carried out by a Faro Focus 3D 120S, which is a phase based TLS instrument with built-in camera. The required time of the measurement depends on the settings of the resolution and quality. The maximum density is $1.5 \mathrm{~mm}$ at $10 \mathrm{~m}$, whilst the nominal ranging error is $\pm 2 \mathrm{~mm}$ [11] (Tab. 4).

During laser scanning the stones were again placed in three different positions, however, all stones were measured simultaneously (Tab. 5). Point spacing for each positions were selected to $3 \mathrm{~mm}$ at 10 meters. Due to the overlapping areas even more dense point clouds were produced. Reference spheres were applied to achieve the precise alignment between the scan stations. Since images were not taken, only the intensity of the objects was captured. 
Table 4 Technical data for Faro Focus 3D 120S

\begin{tabular}{cc}
\hline Measurement method & Phase based \\
\hline Nominal ranging error & $\pm 2 \mathrm{~mm}$ \\
Nominal measurement range & $0.6-120 \mathrm{~m}$ \\
Maximal measurement rate & $976000 \mathrm{points} / \mathrm{s}$ \\
Field of view & $360^{\circ} / 305^{\circ}$ (horizontal $/$ vertical) \\
Maximum angular resolution & $32.4^{\prime \prime} / 32.4^{\prime \prime}$ (horizontal $/$ vertical) \\
Color information & Built-in camera, optionally \\
\hline
\end{tabular}

Table 5 Features of the TLS measurements (Faro Focus 3D 120S)

\begin{tabular}{|c|c|c|c|c|}
\hline & 0048 & 0051 & 0068 & 0121 \\
\hline $\begin{array}{l}\text { Number of scan stations } \\
\text { (position I) }\end{array}$ & \multicolumn{4}{|c|}{7} \\
\hline $\begin{array}{l}\text { Number of scan stations } \\
\text { (position II) }\end{array}$ & \multicolumn{4}{|c|}{6} \\
\hline $\begin{array}{l}\text { Number of scan stations } \\
\text { (position III) }\end{array}$ & \multicolumn{4}{|c|}{6} \\
\hline Resolution (position I, II, III) & \multicolumn{4}{|c|}{$3 \mathrm{~mm} / 10 \mathrm{~m}$} \\
\hline $\begin{array}{l}\text { Number of points after merging } \\
\text { the positions and non-stone points } \\
\text { removal }\end{array}$ & 708350 & 208098 & 505919 & 883698 \\
\hline
\end{tabular}

\subsubsection{Kinect Xbox 360}

The applied depth camera is the Kinect sensor for Microsoft Xbox 360 game console, which enables motion tracking based game control. The sensor was originally developed by the Prime Sense, later Microsoft has acquired the rights of producing the sensor. Despite Kinect was intended to operate as a game controller, it can fully operate as a standalone depth camera [7].

Kinect features two CMOS cameras (theoretically $1280 \times 1024$ pixels, but only $640 \times 480$ pixels are available), one IR emitter, one multi-array microphone and an accelerometer. The circuits inside the device are capable of pre-processing the recorded data.

Table 6 Technical data for Kinect XBOX 360

\begin{tabular}{cc}
\hline Measurement method & Optical triangulation \\
\hline Image resolution & $640 \times 480$ pixel \\
Nominal measurement range & $0.5-3.5 \mathrm{~m}$ \\
Frame rate & $30 \mathrm{fps}$ \\
Nominal accuracy & $1 \mathrm{~cm}($ at $2 \mathrm{~m})$ \\
Color information & Built-in camera \\
\hline
\end{tabular}

The stones were placed in three different positions to be measured by the Kinect (Fig. 5). The image capture was carried out with overlapping areas (Tab.7). The produced point cloud patches were aligned in few steps. The initial positions were drawn up by some markers, then the points of interest were bounded and processed with ICP. Point cloud for each stone was produced by transforming the positions together. Although the remaining errors of each transformation were not significant, the huge number of the performed transformation results perceptible error accumulation.

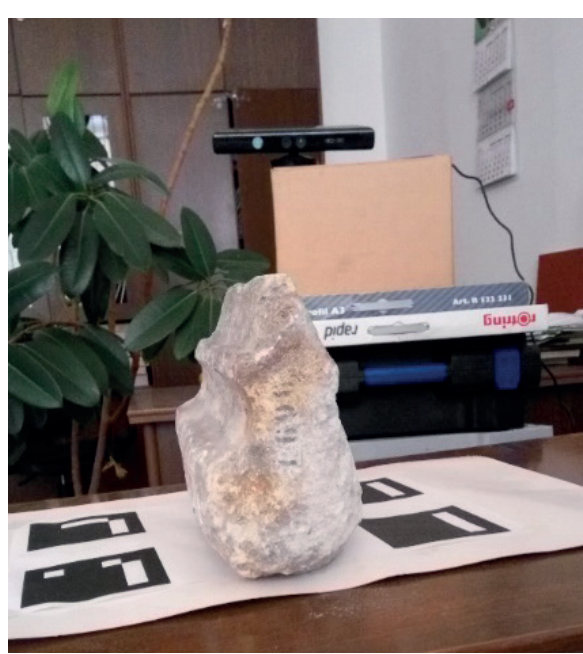

Fig. 5 Measurement with the Kinect Xbox 360

Table 7 Parameters for the depth camera measurements

\begin{tabular}{|c|c|c|c|c|}
\hline & 0048 & 0051 & 0068 & 0121 \\
\hline $\begin{array}{l}\text { Number of aligned } \\
\text { patches (position I) }\end{array}$ & 38 & 17 & 31 & 30 \\
\hline $\begin{array}{l}\text { Number of aligned } \\
\text { patches (position II) }\end{array}$ & 31 & 26 & 34 & 31 \\
\hline $\begin{array}{c}\text { Number of aligned } \\
\text { patches (position III) }\end{array}$ & 40 & 27 & 32 & 36 \\
\hline $\begin{array}{l}\text { Number of points } \\
\text { (position I) }\end{array}$ & 676390 & 117606 & 504863 & 824460 \\
\hline $\begin{array}{l}\text { Number of points } \\
\text { (position II) }\end{array}$ & 744700 & 182139 & 593654 & 675772 \\
\hline $\begin{array}{l}\text { Number of points } \\
\text { (position III) }\end{array}$ & 779625 & 213531 & 502616 & 1181543 \\
\hline $\begin{array}{c}\text { Number of points } \\
\text { after merging patches } \\
\text { and non-stone point } \\
\text { removal }\end{array}$ & 687598 & 440469 & 1021023 & 1835354 \\
\hline
\end{tabular}

\subsection{Developed analysis method}

\subsubsection{The evaluation of the spatial object reconstruction techniques in comparison to the} reference mesh model

The point clouds produced by the applied reconstruction techniques describe the real geometry on different level, so differences between the point clouds and the reference model was calculated. Congruent or similarity transformations were executed for each point cloud to achieve the same position and orientation as the reference model. For depth camera and pixel based reconstruction even scaling was necessary. A two-step method was applied; first an initial state was established with manual marker points, then the final position of the point cloud was achieved using ICP method.

The distances were calculated in the software package Geomagic Control. Since differences higher than $1 \mathrm{~cm}$ can be considered as outliers, only smaller differences have been analyzed (Fig. 7) (Tab. 8). 


\subsubsection{The evaluation of the spatial object reconstruction techniques based on the created mesh models}

Mesh models can be produced in further processing steps, so the stone volume and surface data will be also available. Furthermore, the point density also can be set. All mesh models were derived in Geomagic Studio in two steps. First, a rough model was produced, which was appropriate only for noiseless complete (covering the entire surface of the objects) point clouds. Otherwise a lot of manual editing would be needed for creating the final model. Even after the noise removal one should count with several errors (e. g. self-intersections, highly-creased edges and spikes). These errors can be repaired either manually or automatically.

\subsubsection{Analysis of cross-sections}

The spatial objects can be described by not only mesh models but also vector models or cross-sections. The sections are derived typically from surface models, however, these can also be directly derived from point clouds. $0.3 \mathrm{~mm}$ thick sections obtained from the same positions furthermore enable the evaluation of the achieved models. Additional data can also be derived (district, area, curvature data).

Although the points are nicely representing the particular sections, they can be barely used for further investigations. It is worth to derive vectorized planar features; since creating these features manually takes a long time in case of multiple sections, we decided to find automated solution. The points are typically not equally distributed along the section border; there are dense and sparse segments. Continuous lines were fit on the points using image processing techniques (Fig. 6). After Savitzky-Golay filtering [8], cubic splines were fitted on the vertices of the borders, therefore calculating the area, perimeter and curvatures became available.
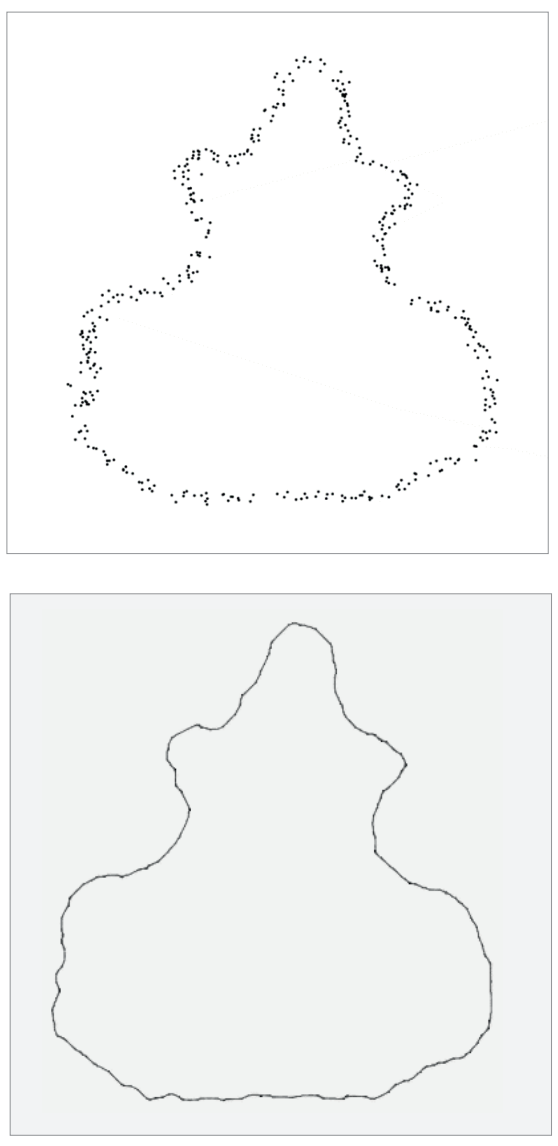

Fig. 6 Point cloud section and the fit cubic spline

\section{Results}

\subsection{Results from reconstruction technique investigation}

Table 8 shows the numerical results of the analysis. Maximum difference shows the range of differences $( \pm 1 \mathrm{~cm})$ that have been considered. In case of stone \#0121 and the Kinect point cloud of $\# 0068$, differences higher than $1 \mathrm{~cm}$ occurred, therefore these have been omitted. Besides calculating an average difference value for the full range, the positive or negative

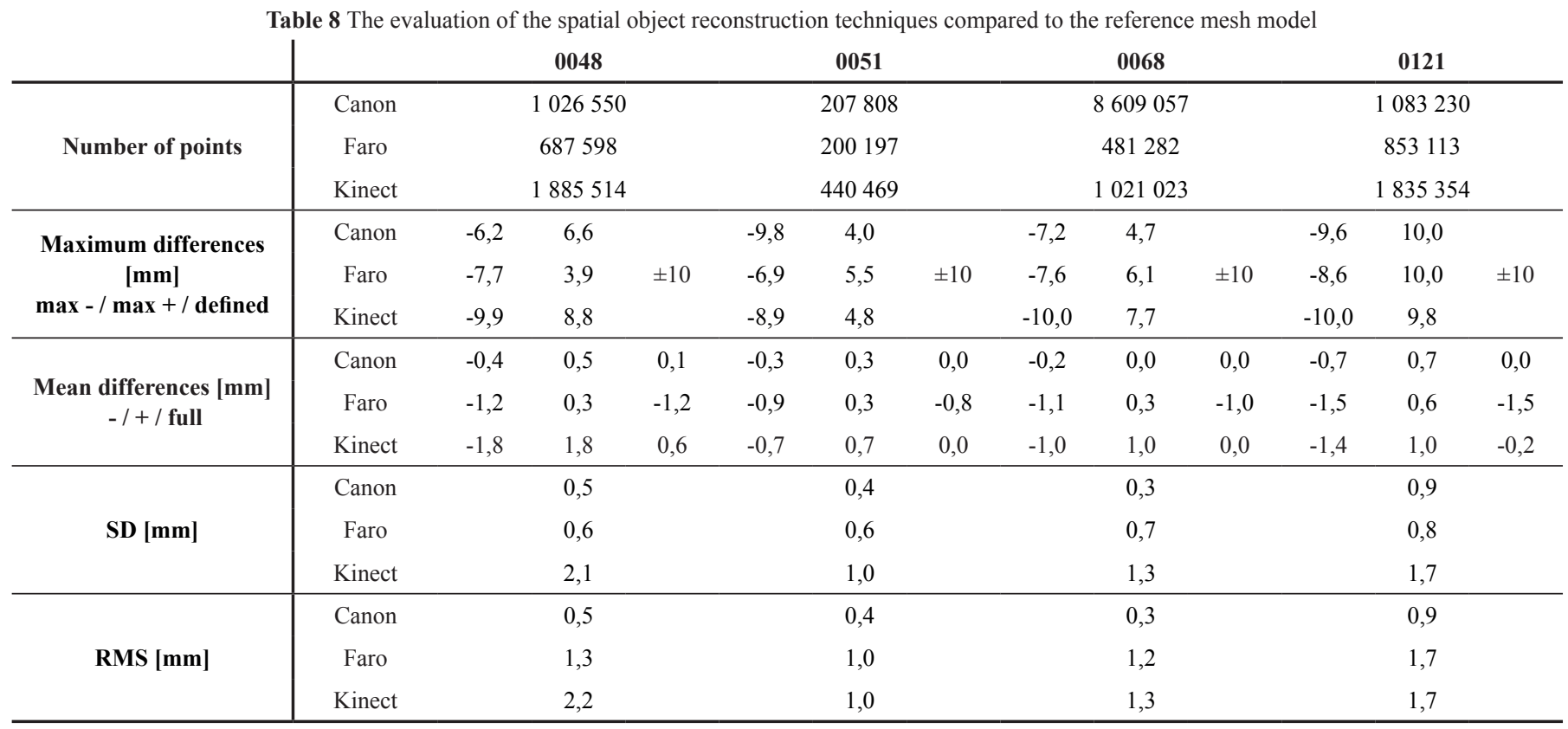




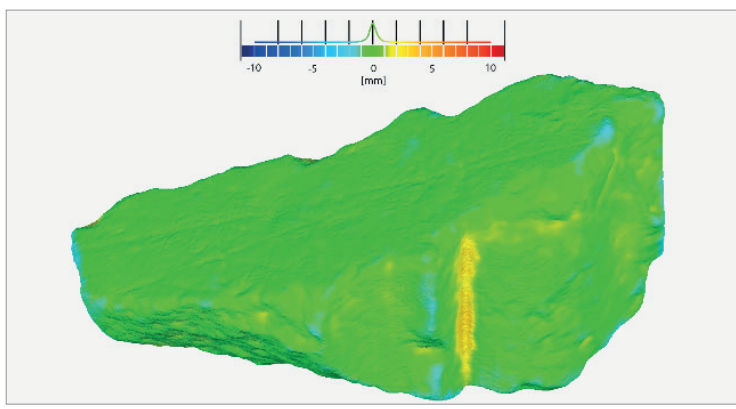

a.) Canon

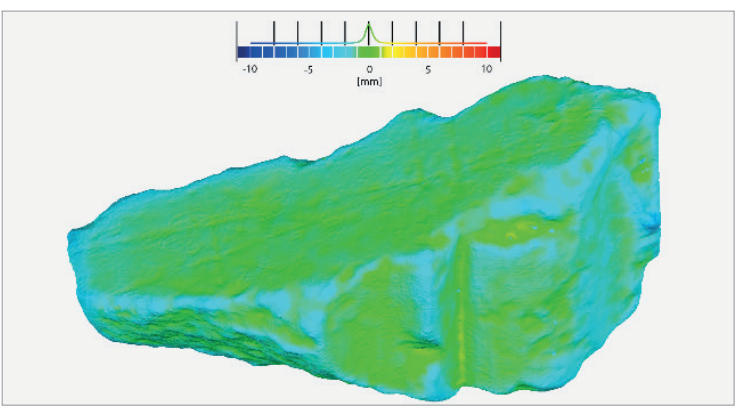

a.) Faro

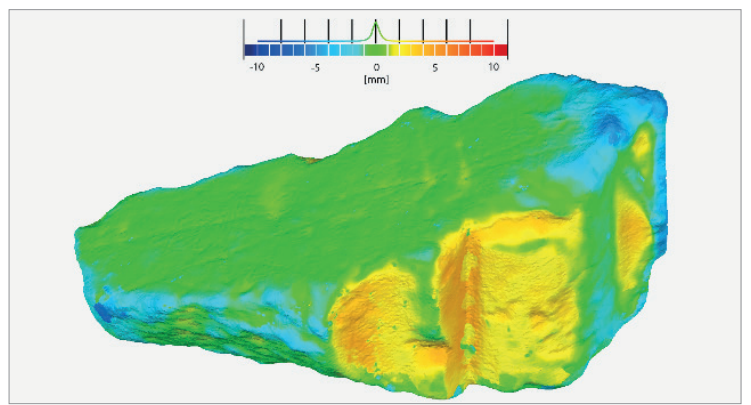

a.) Kinect

Fig. 7 Stone \#0051 Mesh model deviations from reference model

values can only be considered; this is also presented in (Tab. $8)$. The standard deviation (SD) and root mean square errors (RMS) also clearly show the differences between the applied technologies. Based on this analysis the Kinect can be considered as less capable of deriving proper point clouds, while image based reconstruction is a reasonable alternative to SLS.

\subsection{Results from the mesh modelling}

Altogether 16 models have been created (Tab. 9). Surface and volume parameters can be derived from the clean, complete models, i.e. from those that do not contain double surfaces, self-intersections, separated islands, holes etc. Note the extreme high point density in case of \#0068 where we applied ultrahigh densifying settings during the image based reconstruction. In order to analyze volume and surface data we calculated their volume/area ratio and we visualized the differences on diagrams (Fig. 8, 9). It's clear that the derived models nicely represent the surveyed stones, but the models based on TLS are always smaller than that of the SLS. In this particular investigation the image-based reconstruction provided the most accurate and reliable results. Point cloud noise can be reduced by applying specific filter, however, the real local differences can be also removed, and the fine details can be lost, as it can be seen on (Fig. 10).

\subsection{Results from profiles}

Three profiles (A-A, B-B, C-C) have been derived from point clouds, except in case of SLS, where surface model were used to create the sections. According to Section 3.2 the technologies ensures different point density (Tab. 9). Besides the noise level the point density has effect on the border line reconstruction.
Perpendicular section to the selected axis is not possible in case of \#0051, therefore this was excluded from the analysis. The automatic spline alignment resulted outstanding errors in case of \#0121 based on Kinect measurement, so the diagrams do not include those deviations (Fig. 11 12). The resolution of the section based on the reference measurements is so high compared to the others that the perimeter values are smaller in each case. However, it seems that the Canon measurements provided the smallest differences. Note the significant differences in case of Faro and Kinect in Fig. 12; the section areas are typically bigger in case of Kinect, and smaller in case of Faro. For Canon, the values are close to the reference values, the difference does not exceed $1.1 \%$.

\section{Conclusions}

The applied technologies support the modelling of the stone fragments in different ways. Due to high accuracy and geometric resolution, the SLS-based model was selected as a reference. From the other three technologies, the image based object reconstruction provided the most valuable results, the obtained mesh models enable detailed analyses. Regarding the costs, the Kinect is the most affordable, while TLS is the most expensive. Time need is an important issue; while TLS and image-based reconstruction have similar requirements, Kinect has longer duration (Tab 10). It has been proved that the geometry of the investigated stone fragments can be captured in multiple ways, the time-, cost-, accuracy- and resolution requirements determine which should be applied in a particular project. 


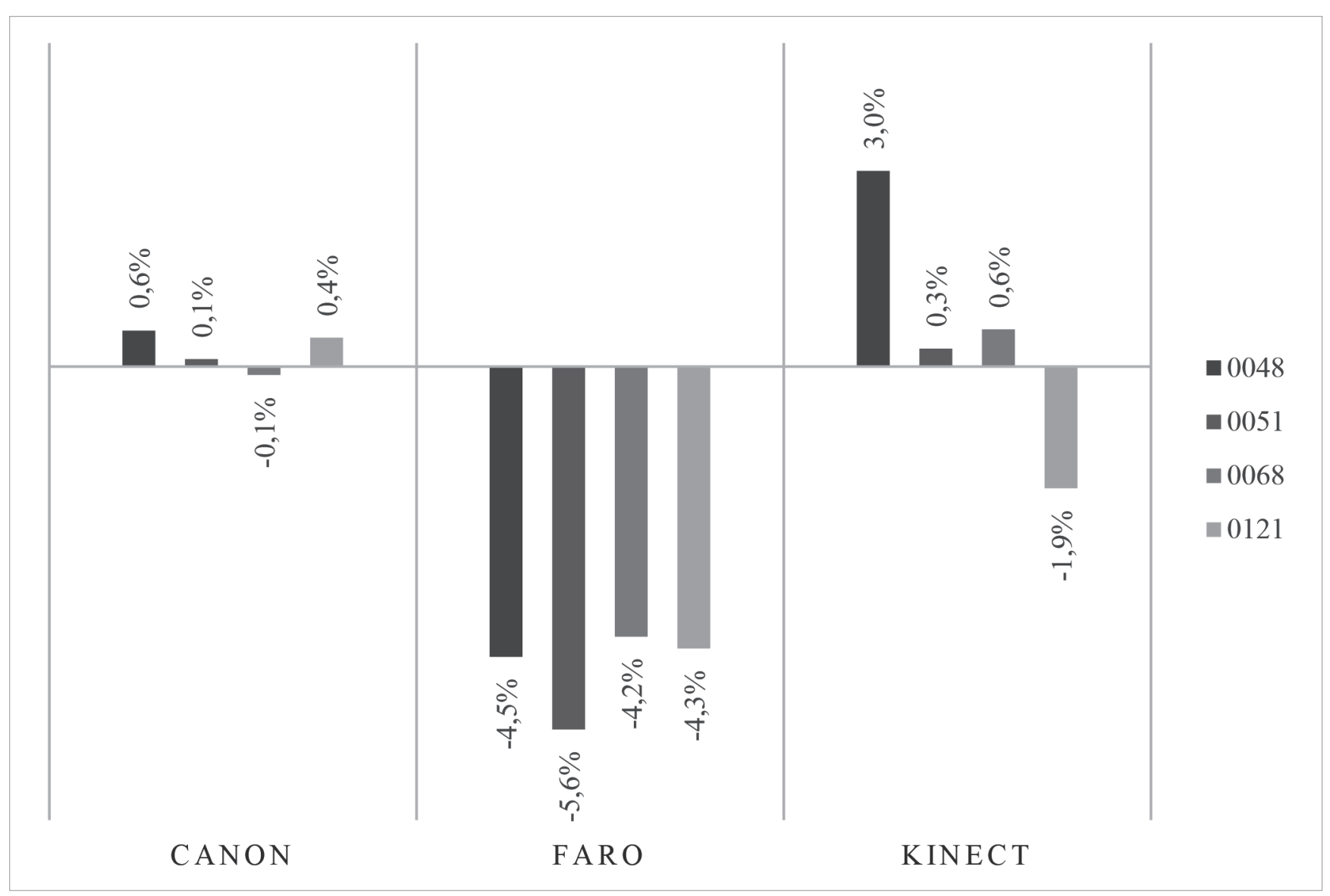

Fig. 8 Volume difference from the reference model

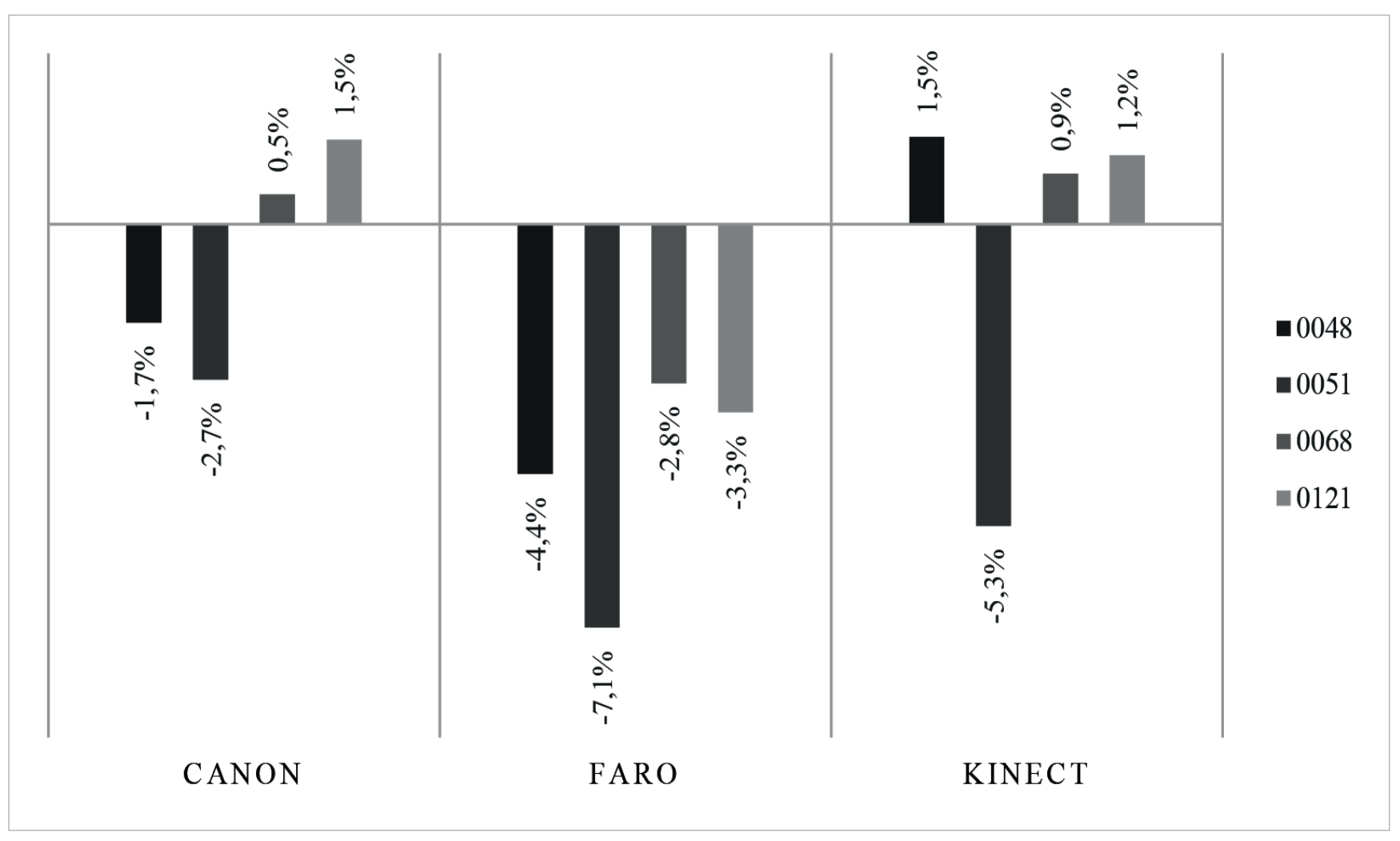

Fig. 9 Surface difference from the reference model 


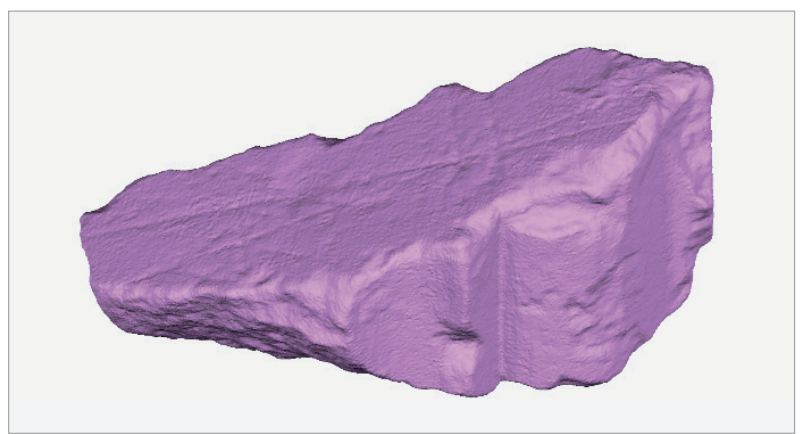

a.) Artec Eva

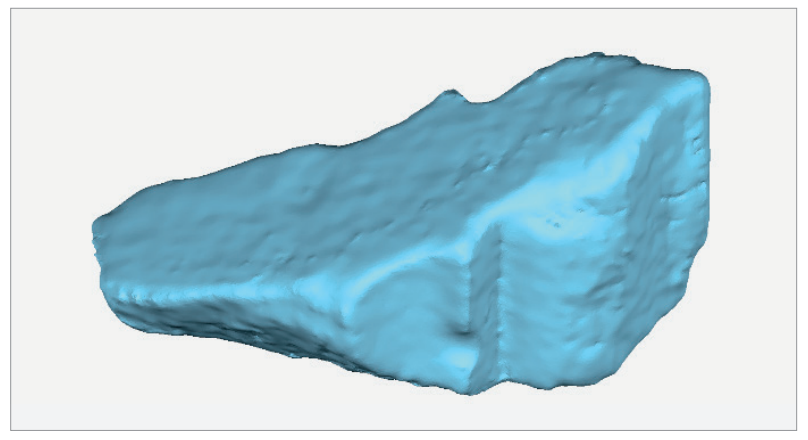

c.) Faro

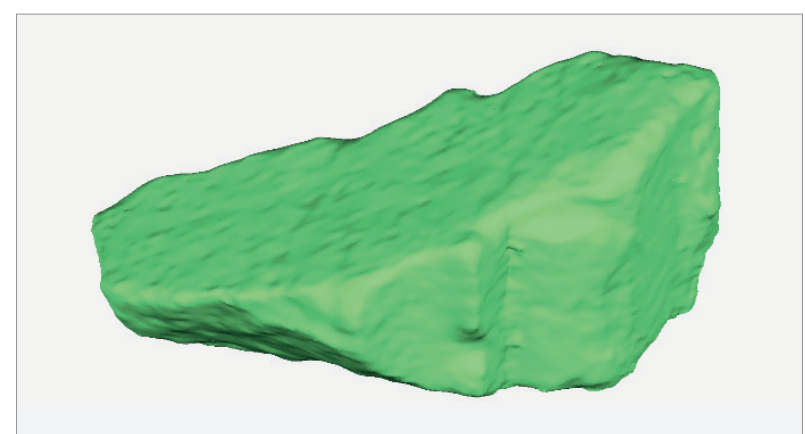

b.) Canon

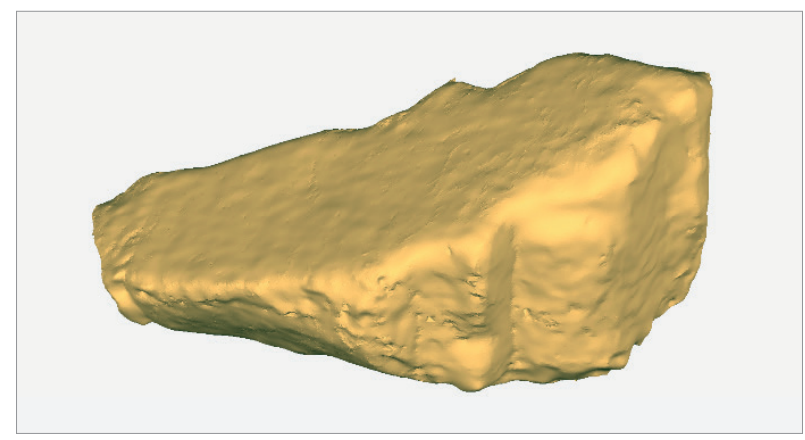

d.) Kinect

Fig. 10 Derived mesh models

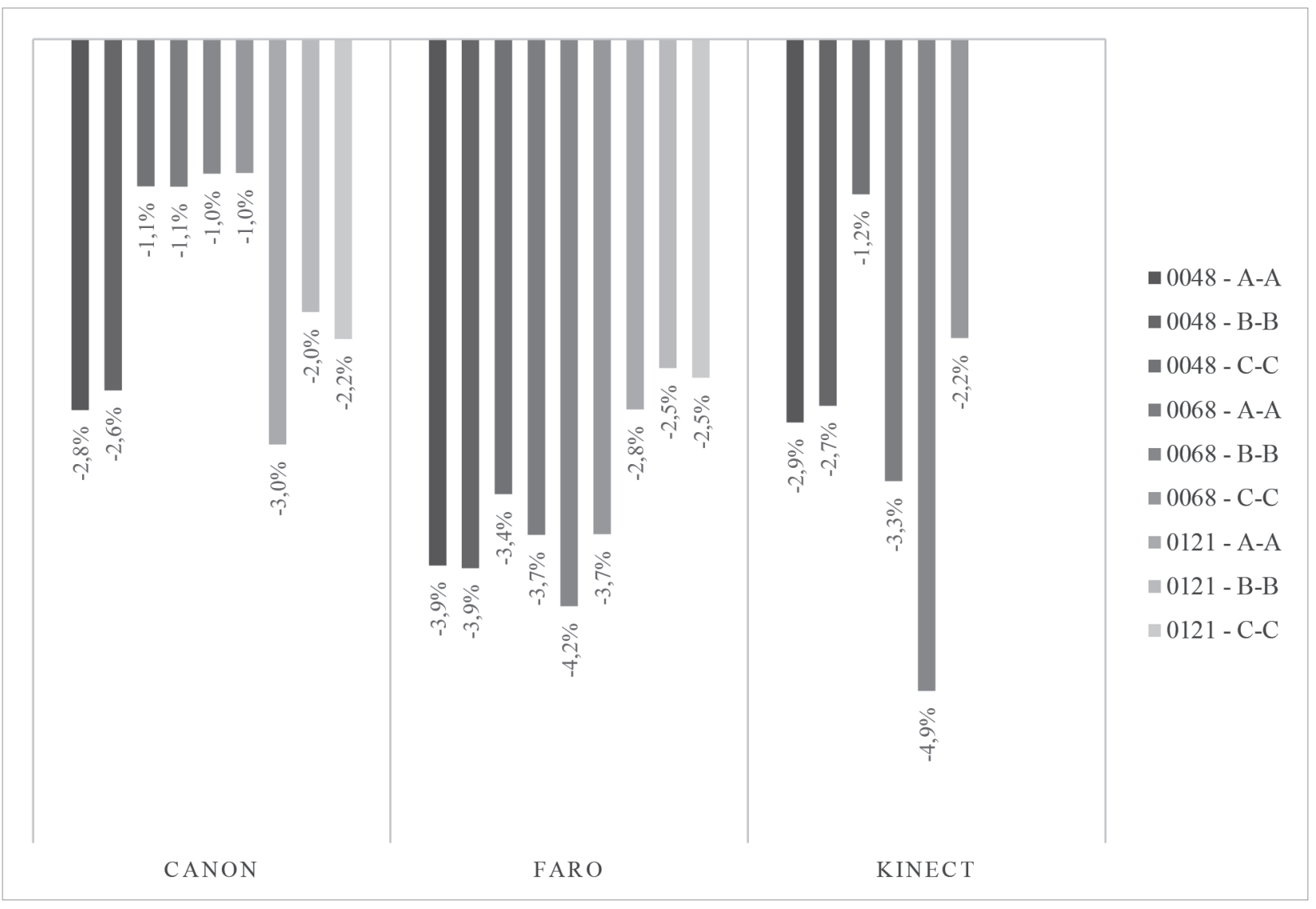

Fig. 11 Perimeter difference from the reference section 


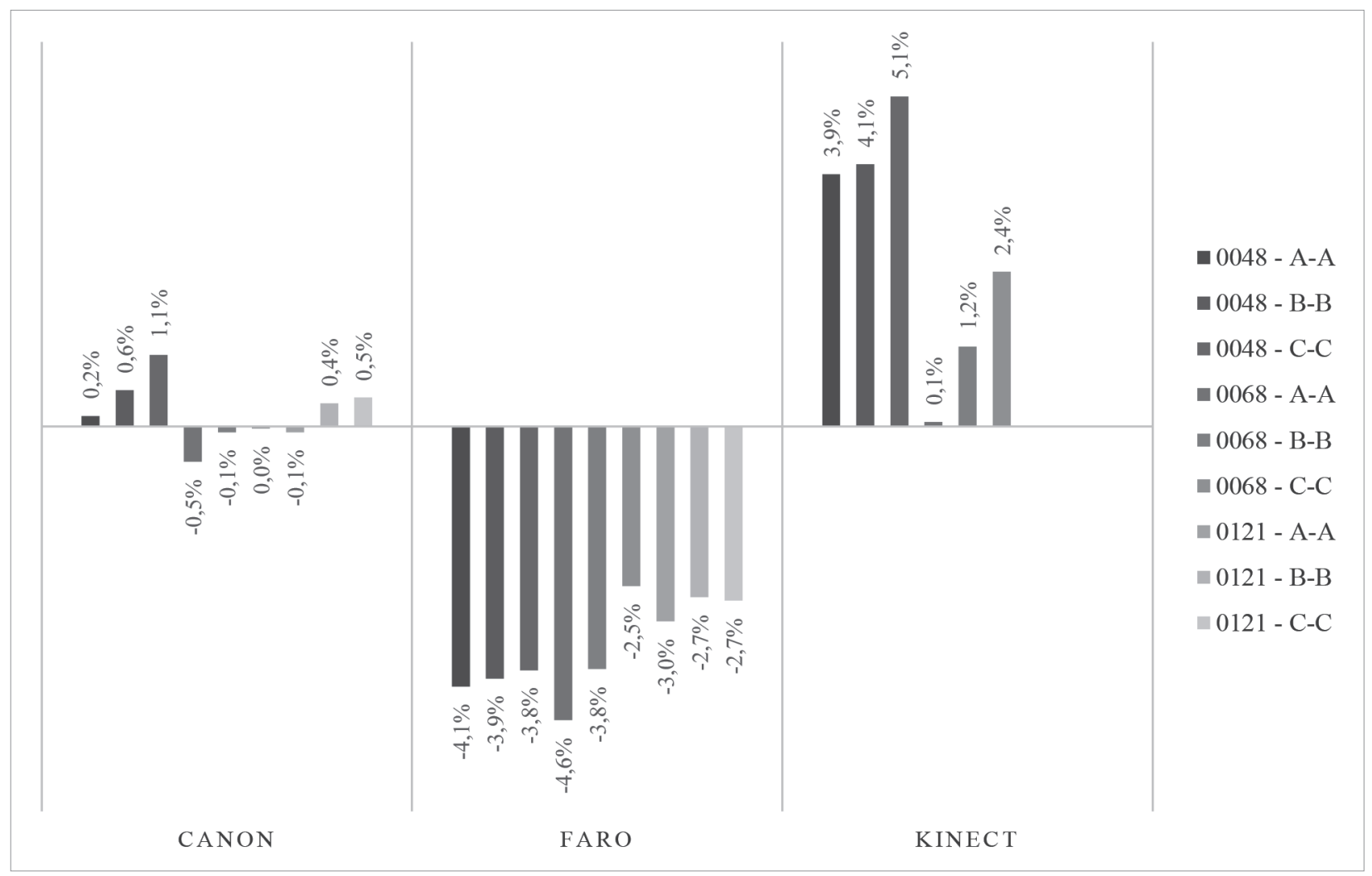

Fig. 12 Area difference from the reference section

\begin{tabular}{|c|c|c|c|c|c|}
\hline & & 0048 & 0051 & 0068 & 0121 \\
\hline \multirow{4}{*}{ Number of triangles } & Canon & 2038358 & 414908 & 17203682 & 2161252 \\
\hline & Faro & 1369074 & 398286 & 959600 & 1701094 \\
\hline & Kinect & 3242139 & 870984 & 1963706 & 3590266 \\
\hline & Artec Eva & 1885740 & 528604 & 1705002 & 3231874 \\
\hline \multirow{4}{*}{ Points $/ \mathbf{c m}^{2}$} & Canon & 469 & 345 & 5548 & 372 \\
\hline & Faro & 323 & 348 & 321 & 307 \\
\hline & Kinect & 834 & 751 & 656 & 632 \\
\hline & Artec Eva & & & & \\
\hline \multirow{4}{*}{ Volume $\left[\mathrm{cm}^{3}\right]$} & Canon & 5758,95 & 875,58 & 3300,30 & 9056,64 \\
\hline & Faro & 5470,55 & 825,56 & 3166,82 & 8624,25 \\
\hline & Kinect & 5900,11 & 877,02 & 3323,49 & 8847,23 \\
\hline & Artec Eva & 5726,90 & 874,56 & 3304,48 & 9016,25 \\
\hline \multirow{4}{*}{ Area $\left[\mathrm{cm}^{2}\right]$} & Canon & 2187,72 & 602,54 & 1551,82 & 2912,78 \\
\hline & Faro & 2128,75 & 575,58 & 1500,72 & 2775,64 \\
\hline & Kinect & 2260,26 & 586,63 & 1557,46 & 2904,95 \\
\hline & Artec Eva & 2226,28 & 619,43 & 1543,83 & 2870,29 \\
\hline \multirow{4}{*}{ Volume - Area Ratio } & Canon & 2,63 & 1,45 & 2,13 & 3,11 \\
\hline & Faro & 2,57 & 1,43 & 2,11 & 3,11 \\
\hline & Kinect & 2,61 & 1,50 & 2,13 & 3,05 \\
\hline & Artec Eva & 2,57 & 1,41 & 2,14 & 3,14 \\
\hline
\end{tabular}


Table 10 Time requirement of measurements

\begin{tabular}{ccccc}
\hline & Artec Eva & $\begin{array}{c}\text { Canon } \\
\text { EOS 760D }\end{array}$ & $\begin{array}{c}\text { Faro Fo- } \\
\text { cus 120S }\end{array}$ & $\begin{array}{c}\text { Kinect } \\
\text { Xbox 360 }\end{array}$ \\
\hline $\begin{array}{c}\text { Duration of the } \\
\text { measurement }\end{array}$ & $\begin{array}{c}15 \mathrm{~min} / \\
\text { stone }\end{array}$ & $\begin{array}{c}15 \mathrm{~min} / \\
\text { stone }\end{array}$ & $\begin{array}{c}120 \mathrm{~min} / \mathrm{all} \\
\text { the stones }\end{array}$ & $\begin{array}{c}60 \mathrm{~min} / \\
\text { stone }\end{array}$ \\
$\begin{array}{c}\text { Duration of the } \\
\text { point clouds } \\
\text { unification }\end{array}$ & - & $\begin{array}{c}100-180 \\
\mathrm{~min} / \mathrm{stone}\end{array}$ & $\begin{array}{c}120 \mathrm{~min} / \mathrm{all} \\
\text { the stones }\end{array}$ & $\begin{array}{c}180 \mathrm{~min} / \\
\text { stone }\end{array}$ \\
$\begin{array}{c}\text { Duration of the } \\
\text { surface modeling }\end{array}$ & $\begin{array}{c}15 \mathrm{~min} / \\
\text { stone }\end{array}$ & $\begin{array}{c}45 \mathrm{~min} / \\
\text { stone }\end{array}$ & $\begin{array}{c}120 \mathrm{~min} / \\
\text { stone }\end{array}$ & $\begin{array}{c}100-240 \\
\mathrm{~min} / \mathrm{stone}\end{array}$ \\
\hline
\end{tabular}

The comparison of these survey methods and the obtained models serve the advancement of historical research which aims the examination of profile shapes as well as the marking lines left by the instruments of stonemasons. Finding the way of generating punctual cross sections is essential for getting information on the factors influencing the geometry of Gothic architectural details. In order to come up with a reasonable hypothesis, a representative amount of cross sections is needed. Having taken all the advantages and disadvantages of the four measuring technology into consideration, in our particular case, image-based reconstruction is likely to be the most effective method.

\section{Acknowledgement}

Authors would like to express their special thanks to András Végh, director of Castle Museum of the Budapest History Museum for providing access to the medieval stone collection and the opportunity to analyze the objects.

\section{References}

[1] Triggs, B., McLauchlan, P. F., Hartley, R. I., Fitzgibbon, A. W. "Bundle Adjustment - A Modern Synthesis.” In: Proceedings of the International Workshop on Vision Algorithms: Theory and Practice. pp. 298-372. 2000.

[2] Bay, H., Ess, A., Tuytelaars, T., Van Gool, L. "Speeded up robust features (SURF)." Computer Vision and Image Understanding. 110, pp. 346-359. 2008. DOI: 10.1016/j.cviu.2007.09.014

[3] Lowe, D. G. “Object recognition from local scale-invariant features.” In: Proceedings of the International Conference on Computer Vision, 1999. pp. 1150-1157. 1999. DOI: 10.1109/ICCV.1999.790410

[4] Posdamer, J. L., Altschuler, M. D. "Surface measurement by space-encoded projected beam systems." Computer Graphics and Image Processing. 18 (1), pp. 1-17. 1982. DOI: 10.1016/0146-664X(82)90096-X

[5] Lovas, T., Berényi, A., Barsi, Á. “Laser scanning.” 166 p. Terc Kiadó, Budapest. 2012. (In Hungarian)

[6] Lovas, T., Somogyi, J. Á., Török, Á., Koppányi, Z., Molnár, B. “Supporting rock-fall risk analysis of cliff faces by terrestrial laser scanning and UAV imagery.” In: Imaging \& Geospatial Technology Forum (IGTF), Fort Worth, USA. 5 p. 2016.

[7] Molnár, B., Toth, C. K., Detrekői, Á. “Accuracy test of Microsoft Kinect for human morphologic measurements." International Archives of the Photogrammetry, Remote Sensing and Spatial Information Sciences. Vol. XXXIX-B3, pp. 543-547. 2012. DOI: 10.5194/isprsarchives-XXXIXB3-543-2012

[8] Savitzky, A., Golay, M. J. E. "Smoothing and Differentiation of Data by Simplified Least Squares Procedures." Analytical Chemistry. 36 88), pp. 1627-1639. 1964. DOI: 10.1021/ac60214a047
[9] Artec 3D. "Professional 3D scanning solutions." 2016. https://www.artec3d.com/files/pdf/ArtecScanners-Booklet-EURO.pdf

[10] Agisoft. "Agisoft PhotoScan User Manual: Professional Edition, Version 1.2.” 2016. http://www.agisoft.com/pdf/photoscan-pro_1_2_en.pdf

[11] FARO. "FARO Focus 3D." 2016. http://www2.faro.com/site/resources/ share/944

[12] Fehér, K., Halmos, B. “A középkori építészet szerkesztési módszerei a hazai szakirodalom tükrében.” (Architectural Design Methods of the Middle Ages by the Hungarian Historiography.) Épités - Épitészettudomány. 43 (3-4), pp. 237-284. 2015. (In Hungarian) DOI: 10.1556/096.2015.43.3-4.7

[13] Papp, Sz. “Constructions of the Royal Court in Hungary 1480-1515.” 297 p. Balassi, Budapest. 2005. (in Hungarian)

[14] Nagy, E. "Catalogue of Carved Stones from the Medieval Royal Palace of Buda I." manuscript ,1994. (in Hungarian)

[15] Várnai, D. "Morphological Development of Medieval Vault Ribs in Buda Castle.” Budapest Régiségei. 16, pp. 363-371. 1955. (In Hungarian)

[16] Murray, S. "Plotting Gothic: A Paradox." Architectural Histories. 2 (1), Art. 16. 2014. DOI: 10.5334/ah.bs

[17] Hajnóczi, Gy. "Monument Survey.” Építőipari Müszaki Egyetem Tudományos Közleményei .1 (6), p. 74. 1956. (In Hungarian)

[18] Cramer, J. „Handbuch der Bauaufnahme.“ 151 p. Deutsche Verlags-Anstalt, Stuttgart. 1993. (In German) https://www.amazon.de/HandbuchBauaufnahme-Johannes-Cramer/dp/3421028168

[19] De Jonge, K., Van Balen, K. "Preparatory Architectural Investigation in the Restoration of Historical Buildings.” 219 p. Leuven University Press, Leuven. 2002. https://www.amazon.com/Preparatory-Architectural-Investigation-Restoration-Investigata/dp/9058672506

[20] Halmos, B., Marótzy, K. "The adaptation of the true-to-form survey method." Periodica Polytechnica Architecture. 41 (1), pp. 9-17. 2010. DOI: 10.3311/pp.ar.2010-1.02

[21] Fehér, K., Halmos, B. "Research of Medieval Constructing Methods in the Oeuvre of István Möller.” Müemlékvédelem. 60 (1-2), pp. 86-100. 2016. (In Hungarian)

[22] Szekér, Gy. "Theoretic Reconstruction as a Research Method - Study on the Niche-Vaulting on the Southern Wall of Diósgyör Castle." In: Régészeti Kalandozások. pp. 27-32. 2014. (In Hungarian)

[23] Szöke, B. "Computer Analysis of Vaulting Reconstructions and Vaultings.” In: Reneszánsz látványtár - Virtuális utazás a múltba. Magyar Nemzeti Múzeum, Budapest. pp. 443-461. 2009. (In Hungarian)

[24] Bauer, T., Lauterbach, J. „Schlingrippengewölbe - Höhepunkt spätgotischer Steinmetzkunst.“ STEIN. 11, pp. 30-35. 2014. (In German)

[25] Bauer, T., Lauterbach, J. „Die Schlingrippen der Gewölbe““ 214 p. 2011. (In German) 